\title{
LNG Import Contract in the perspective of Associated Technical and Managerial Challenges for the Distribution Companies of Pakistan
}

\author{
Kawish Bakht \\ Department of Engineering Management \\ National University of Sciences and Technology \\ Islamabad, Pakistan \\ Farhan Aslam \\ Department of Engineering Management \\ National University of Sciences and Technology \\ Islamabad, Pakistan
}

\author{
Tahir Nawaz \\ Department of Engineering Management \\ National University of Sciences and Technology \\ Islamabad, Pakistan \\ Bakhtawar Seerat \\ Department of Computer Engineering \\ National University of Sciences and Technology \\ Islamabad, Pakistan
}

\begin{abstract}
Energy Managers and Government Office Holders in Pakistan are nowadays pondering over multiple options for the resolution of ongoing Energy crises in the country.

LNG (Liquefied Natural Gas) import has been finalized for being the quickest remedy among all the available options. LNG (Liquefied Natural Gas) contract is at the verge to be implemented in Pakistan. However there are several factors that need to be addressed while implementing the project. In this paper, identification of the challenges affecting the optimized distribution of gas is presented. The sustainability of LNG (Liquefied Natural Gas) Project depends upon the successful running of the project without facing any financial crises arising from the gas distribution losses. The motive of this paper is the identification of the factors that are risk for the sustainability and successful running of LNG Import in Pakistan on long term basis. In association it is required to identify technical and managerial challenges for the gas distribution companies in distribution of LNG. Moreover recommendations are proposed for modification in existing infrastructure and governing policies related to gas distribution companies for logical success and long term sustainability of LNG import in Pakistan.
\end{abstract}

Keywords-LNG Import Contract; sustainable energy solution; UFG (Unaccounted for Gas) losses; Infrastructure and policy Amendments; Technical and Managerial Challenges

\section{INTRODUCTION}

LNG (Liquefied Natural Gas) Import Contract for Pakistan has been perceived by the Energy Managers of the day as the quickest possible and least objectionable solution in the perspective of internal and external pressures. The LNG import from Qatar has been finalized by the Energy planners of Pakistan. The options under discussion are ranging through IP (Iran-Pakistan) Gas Pipeline Project, TAPI (Turkmenistan, Afghanistan, Pakistan \& India) Gas Pipeline Project, QatarPakistan Undersea Pipeline/ LNG import from Qatar, Energy Sector Cooperation with China to USA's Cooperation in Energy Sector. The realistic approach is to consider the merits and de-merits of every project after critical analysis rather doing something in emotional or fearful state of affairs. Moreover wisdom is, to prioritize these projects in the short and long term plans for Resolution of Energy Problems. The time requires us to consider the sustainable Resolution of Energy Sector crises rather than short term whims. There is nothing worse than having no option. Therefore, every option should be perceived in a realistic manner in the preview of National Energy Requirements and consumption sectors.

Pakistani Government has taken the practical initiative on the import of LNG from Qatar which is the quickest possible solution available among the less controversial options. The first LNG ship has arrived at the Arabian Sea, where it was welcomed in country with criticism, confusion, hope and whims. The debate is still there going on, for finalization of decision regarding the probable end users and beneficiaries. The Government has started importing the LNG (Liquefied Natural Gas) but concrete analysis about the associated challenges for feasible distribution of fuel costlier than domestic natural gas seems unexplored by the decision makers. The LNG is costing three times higher than domestic gas as fuel. At present it is supposed to become the $10 \%$ share holder in the total gas based energy sector of Pakistan but shall expand to fulfill the all the demand gap in future. The gas Energy infrastructure of Pakistan is based on the monopoly/oligopoly of SNGPL (Sui Northern Gas Pipelines Limited) and SSGC. Both are having the status of being sole players in their respective terrains within the Country. Both the gas companies are supplying gas through their pipeline structure and at the expense of pipeline losses ranging from $10 \%$ to $13 \%$ which are referred to as UFG losses (Unaccounted for gas losses) [1], [2] \& [3].

These UFG (Unaccounted for Gas) losses include operational \& accounting losses. The Oil \& Gas Regulatory Authority (OGRA) remains conflicting with the two distribution companies over the permissible percentage of losses called UFG benchmark. UFG Benchmark may be considered limiting line for allowed Gas Distribution losses. 
Those Losses which are considered beyond the control of distribution companies are exempted of any imposed financial penalty as determined by the Regulatory. The Companies are complaining about their constraints in terms of choice of consumers, infrastructural flaws, unionized staff, old gas distribution networks and working capacity constraints. Therefore the LNG distribution by the same gas distribution company infrastructures and using their existing pipeline network is definitely having losses.

The question arises "Is the Pakistani Regulatory Authority (OGRA) ready to allow the losses for an imported LNG fuel which is much costlier as well?" The failure in successful Distribution of LNG among consumers would end up in Chaos for energy sector which is already gasping. The whole activity must be financially feasible for sustainable future of LNG import.

A change in policies and infrastructure of these companies is required else LNG dream may become nightmare without any effort. The aim of this paper is to identify the technical and managerial challenges, the associated risks in LNG distribution in existing structure of gas distribution companies. It includes analysis of risks which may jeopardize the LNG solution for national energy Sector of Pakistan.

\section{LNG IMPORT \& ITS DISTRIBUTION}

The LNG import planned by the national decision makers is either to test their efforts in helping the gasping energy sector, or to build their good reputation for efforts in resolution of Energy crises. Initially the LNG sale was offered to IPPs (Independent Power Producers; private electrical power producing companies) and fertilizers i.e. the corporate clients. But the Sale of LNG being costlier than the Country's own natural gas had received a varying response from the corporate Corners. Some consumers have accepted the offer in preview of current gas load curtailments and gas load shedding. But on the other hand some consumers have rejected the proposal for being costlier fuel than natural gas and furnace Oil. CNG Sector which was facing severe gas curtailment crises in the ongoing perspective of gas load management, have shown their interest in purchasing LNG from SNGPL specifically in the areas of Punjab and Islamabad.

Since LNG is there and LNG import Stakeholders has to decide the ultimate category of consumers for being the end user of LNG, various options are under consideration. CNG Association is using all of its probable channels for being the most suitable candidate. However Government can't afford to financially loose this project. The distribution companies were also not willing to accept the liability of associated losses. The companies know their capability and the condition of their pipeline networks therefore are reluctant to use their distribution network for the Costlier LNG fuel after degasification (R-LNG). If this happens then the accounts of the companies listed on the stock exchange would definitely have to face bearish trend. The distribution companies can't afford the liability of losses for LNG. These gas companies are already under litigation with OGRA on the Legal forums for revision of Bench Mark of UFG losses and penalty imposed on losses by the Regulatory.
The LNG importers has not worked out any other option for LNG infrastructure but has opted for using the existing gas network of the distribution companies. The Companies were initially reluctant for the LNG sale to every consumer with exception to the corporate clients where at the end of Transmission network SMS cum CMS (SMS; Sales Metering Station. Where gas is measured and passed for sale in distribution network. CMS; Consumer Metering Station. Where gas is measured and passed for consumption by consumer) can deliver the gas while avoiding the fuss of distribution network losses.

The distribution network is a giant interconnected structure of pipelines which is approximately $95000 \mathrm{KM}$ for SNGPL and having consumer of every category located on it. Control over the distribution network depends upon multiple factors ranging from controllable to uncontrollable aspects.

For selling LNG to CNG Stations it has to be transported in the distribution network. These CNG Stations are located in every hook and corner of the metropolitan cities and highways having no initial planning for standard minimum distance. The CNG stations are located on the same distribution network which is gasping with low pressures having consumers of every category located on the same pipeline network. LNG would just get lost in the black holes of the distribution pipelines network and scenario won't change.

No one is willing to bear the financial liability of the associated gas distribution network losses. These results from reasons including poor workmanship in developmental activity, politically altered Engineering Designs of pipeline networks, and capacity constraints to cater the operational load while maintaining the good standards. SNGPL is greater in network size and infrastructure than the SSGC, therefore may be used as reference from now onwards to discuss the distribution company.

However in the most recent development SNGPL and SSGC have agreed for distribution of LNG after hot debate on the corporate arena. Though initially it is being carried out on limited scale but have a future extension plan of this project on larger scale. The LNG dedicated line laying process is under progress for SNGPL. At present SSGC is feeding its system with Re-gasified LNG imported on the shore and leaving the domestic gas share as swap for SNGPL as temporary arrangement till construction of dedicated pipeline for $\mathrm{Re}$ gasified LNG. There is difference in the calorific values of the domestic natural gas and LNG. SNGPL has selected from existing consumers for LNG which are non-defaulters and willing to accept the terms and conditions.

\section{BRIEF REVIEW OF LNG IMPORT CONTRACT [4-8]}

Pakistan State Oil (PSO) has been mandated by Government of Pakistan for LNG purchase. Three LNG import options were being considered by Government of Pakistan which are:

\section{1) Government to Government basis with Qatar.}

2) Through international open tendering process. 


\section{3) through spot purchase from pre-qualified suppliers.}

As per LNG transaction structure, PSO will import LNG and SNGPL and SSGC will purchase their notified shares (2/3 - SNGPL \& 1/3 - SSGC) of LNG from PSO. These companies would onward sale it to their respective customers. This will be done through an agreement between PSO, SNGPL and SSGC. LNG re-gasification facility would be required at Karachi port. ENGRO ELENGY (A Pakistani private limited company) will provide LNG re-gasification services at Port Qasim. LNG Services Agreement (LSA) was signed between SSGC and ENGRO ELENGY Terminal Private Ltd (EETPL) on $30^{\text {th }}$ April, 2014, for storage and re-gasification of LNG. EETPL will use Floating Storage \& Re-gasification Unit (FSRU) to convert LNG into vapor phase.

\section{SALIENT FEATURES OF EETPL \& SSGC LNG SERVICE AGREEMENT (LSA)}

The first gas consignment was due on $30^{\text {th }}$ March 2015, with terms of agreement for fifteen years. The scope of Engro Elengy Terminal Private limited EETPL is comprising of the responsibility of Jetty and other marine structures, Dredging of terminal basin, Floating Storage and re-gasification unit (FSRU) and connecting pipeline up to SSGC Network.

\section{MAJOR PROJECT COMPONENTS}

\section{$\checkmark$ LNG SUPPLY \\ $\checkmark$ RE-GASIFICATION \\ $\checkmark$ GAS DISTRIBUTION}

Volume for First year import would be 200 MMCFD (1.5 MTPA LNG) and VOLUME for second year to fifteenth year import would be 400 MMCFD (3 MTPA LNG). It means it would be $10 \%$ of the current 4 BCF gas available in country. LNG Allocation for SNGPL is $2 / 3$ rd and for SSGC is $1 / 3^{\text {rd }}$. Imported LNG is planned to replace expensive liquid fuel in power sector.

SSGC has invited bids from the interested parties to provide LNG Storage and Re-gasification Services by construction of 2nd LNG Terminal at Port Qasim. For this purpose a tender has been floated in Oct, 2014. The terminal capacity is 400 to 500 MMCFD with fifteen years of contract term. The Bid submission date was $15^{\text {th }}$ JAN 2015 and allowed period for first gas supply was set for maximum of 24 months from execution of LSA (LNG Services Agreement). plan.

The above facts and figures are based on the initial work

However later on LNG Project had to incorporate changes arising from the criticism, opposition and proposals. The demand of CNG Association to be a partner in the business of LNG import by development of Universal Gas development company (UGDC) was also a basis of present changes.

UGDC was not having gas pipeline infrastructure. Moreover due to solid realities that it was not granted NOC (No Objection Certificate) from OGRA and Ministry. UGDC had the plan to pay traffic charges to SNGPL for carrying RLNG through its distribution network but nobody was willing to bear the UFG losses during transportation.
For the distribution companies the traffic charges are meaningless in the face of UFG losses during transportation. The two Companies were not willing to undertake the liability of losses as they already pleaded their case of UFG Benchmark in Courts and Council of Common Interests to secure their eroding profitability. In this scenario an additional liability of transporting a costlier fuel for some other new competitor is really a great risk for the company businesses.

However it was considered appropriate to acquire project insurance and leave this responsibility on the shoulders of two existing gas companies i.e. SNGPL and SSGC rather than allowing any new player for LNG distribution due to infrastructure constraints and timeline requirements.

However long term success, is realistically based on the infrastructure and policy amendments for sustainable results of LNG import Project without damaging any stakeholder.

IV. OGRA'S (OIL \& GAS REGULATORY AUTHORITY) DEFINED CONSUMER CATEGORIES FOR THE GAS DISTRIBUTION

COMPANIES AND CHOICE OF FAVORITE CONSUMER FROM BUSINESS PERSPECTIVE

The OGRA has defined the following major four classifications of consumer categories from operational and tariff perspectives. [9]

1) Industrial Consumers

2) Commercial Consumers

3) Domestic Consumers

4) Special Domestic/ Bulk Consumers.

The further detailed categories of the consumers as per OGRA are:

I. Domestic Sector / Special Domestic (i.e. Charitable organizations and Government Sector)

II. Commercial

III. Special Commercial (Roti Tandoors)

IV. Ice Factories

V. Industrial

VI. Compressed Natural Gas (CNG) Stations

VII. Cement

VIII. Fertilizer Companies

IX. Power Stations (WAPDA's and KESC's Power Stations)

X. Independent Power Producers

XI. Captive Power.

The above categories of consumers can further be classified based on the gas quantity required by consumers and business nature as per gas sales contract which are

(A) Corporate Consumer (Power, Fertilizers \& Cement)

(B) Bulk Consumers (Industry, Bulk Commercial \& Bulk Domestic)

(C) Retail Consumers

Gas Distribution companies always prefer Corporate Consumers for their business. Corporate Consumers are better as they require less hectic operational efforts and also probability of pilferage/losses is low. They can be monitored 
easily for comparatively much larger volume of gas than other small retail consumers. The Bulk consumer is ranked second favorable consumer and the retail consumer is the least favorable consumer from business point of view for gas distribution companies. It is similar to the fact that the measurement errors though very small multiplied by a large number of consumers produce an inevitable percentage of loss. An unrealistic number of resources are required for rectification of such no. of measurement errors of equipment if ever possible.

\section{Total loss $=\mathrm{L}$ (Loss for every individual gas consumer) $\times \mathbf{N}$ (Total Number of consumers)}

Therefore the corporate and bulk consumers being small in number are comparatively easier to manage from operational perspective. The retail consumers being large in number are difficult to manage within limited resources.

Moreover, the cost-benefit analysis of the gas consumers also justifies this fact that Corporate and bulk consumers justifies better cost benefit advantage in comparison to the retail gas consumers which are also enjoying subsidy in billing tariff.

\section{UFG \& LOSSES IN THE NETWORK OF SNGPL}

Unaccounted for Gas (UFG) can be defined as the difference between the total volumetric amount of gas available for sale to a transmission or distribution system and volumetric amount of gas billed \& sold.

Formula for calculating \% age UFG losses:

UFG $(\%)$ losses $=\underline{\text { Gas available for Sale-Metered Gas Sold } \mathrm{x}}$ 100

Gas available for Sale

The UFG losses can be further categorized into following two types: [10]

\section{1) Operational losses}

\section{2) Accounting losses}

(a) Operational Aspect of Unaccounted for Gas losses Operational UFG losses include the following categories

a. Gas Network Leakages

b. Measurement Errors in metering Gadget

c. Gas Pressure Regulations

d. Third Party Damages for Gas pipeline network

e. Construction Activity in the area where underground gas infrastructure is present

f. Theft of gas by Pilferers

(b) Accounting Aspect of Unaccounted for Gas losses Accounting UFG losses include the following categories

a. Gas Contractual errors

b. Data Entry errors in the database of Customer Care \& Billing (CC\&B)

c. Cycle Billing errors

d. Report Compilation errors e. Chart Integration errors

f. Pending Punching of new activities in CC\&B sytem database.

SNGPL's Network losses can be specifically summarized in the fig 1 :

\section{FACTORS CONTRIBUTING TO UFG LOSSES IN SNGPL}

There are multiple factors contributing to UFG losses in the network of SNGPL which can be further categorized as controllable, semi-controllable and uncontrollable. [11] and [12]

\section{Controllable Factors:}

$\square$ Poor workmanship

$\square$ Quality of material

$\square$ Leakages in new and rectified gas connections

$\square$ Measurement errors

B Billing errors

口 Gas Network Rehabilitation i.e. Very old / leaking distribution network and budgetary constraints to replace the identified network

口 Accounting Errors

\section{Semi-Controllable Factors:}

- Third party damages

$\square$ New EVC (Electronic Volume Corrector) tampering techniques being adopted by gas pilferers (use of magnets to retard the magnetically coupled driving dock/dog of mechanical counter of Industrial gas meters etc.)

$\square$ Theft of gas where slight public resistance is faced

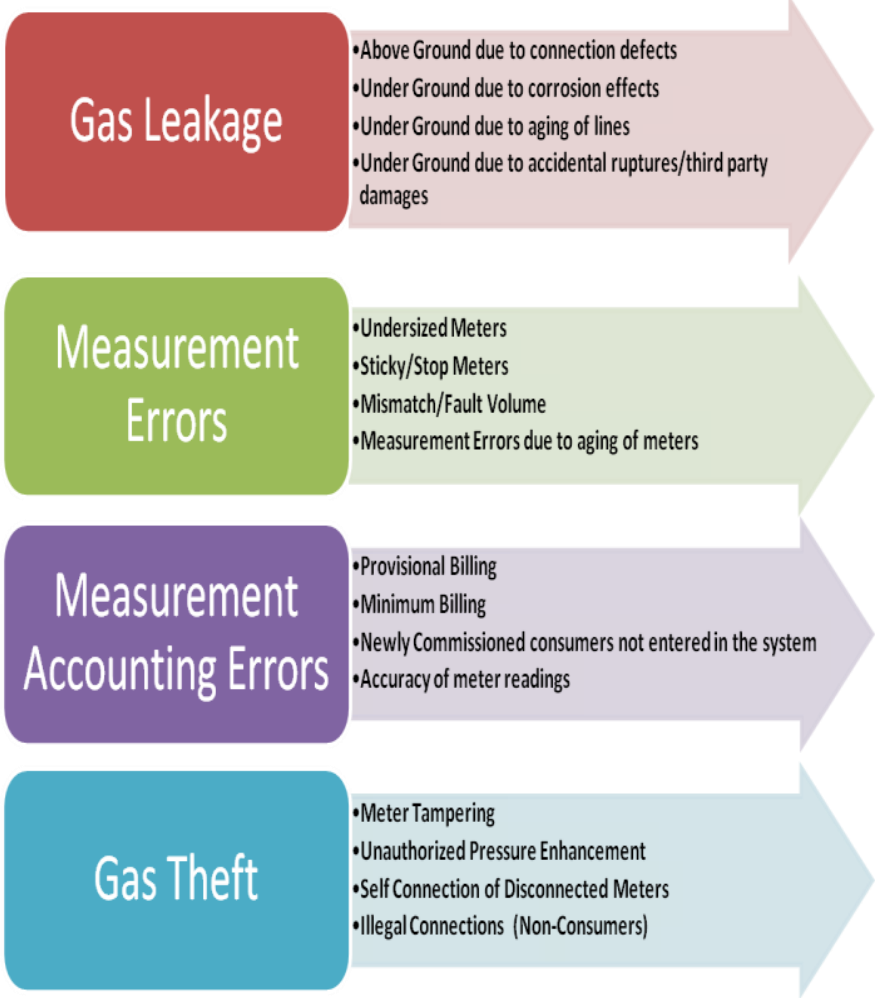

Fig. 1. Summarized Reasons for UFG Losses 


\section{Un-Controllable Factors:}

- Shift of gas from Bulk to Retail sector consumers. Losses in bulk sector are minimal and vice versa.

- Continuous extension of distribution network (Sociopolitical factors in Gas Network Development/extension).

Gas theft by non consumers.

L Litigant gas pilferers and slow processing of cases at different legal forums. Cases pending in Courts.

- Losses in Law and Order affected, Gas producing Areas in Southern Districts of KPK Province.

a Non cooperative attitude of Police / Law Enforcing Agencies for control of Gas Theft.

- Paucity (slow pace) of annual gas connection targets compared with the gas applicants.

- Increased Gas Prices regulated by OGRA and the public having no dependable alternative regular fuel at national level for consumption.

Few of the factors as mentioned above are beyond the control of SNGPL. Therefore devising better policy can resolve these issues.

For example; Paucity in new gas connection provision arising from its low annual targets allocated compared to the total gas applications received, need to be addressed by devising a better policy.

\section{FINANCIAL IMPACT OF UFG AND PROFIT EROSION}

The financial impact of UFG can be well understood by using a quick math calculation.

\section{A Quick Math Calculation}

$$
\begin{array}{lll}
\checkmark & \text { SNGPL Annual UFG } & =68,837 \text { MMCF }(10.20 \%) \\
\checkmark & \text { SNGPL Per day UFG } & =189 \text { MMCFD } \\
\checkmark & \text { Avg. Cost/MMCF } & =\text { Rs 288,190 }
\end{array}
$$

\section{$\underline{\text { Financial Cost of Lost Gas (UFG) }}$}

$$
\begin{aligned}
& \text { 68,837 (MMCF) x Rs 288,190 (Gas price) } \\
& =\text { Rs 19,838 Million }
\end{aligned}
$$

Such a huge amount from the national exchequer is lost annually due to the UFG losses.

\section{(All above figures for FY-2011-12, declared by OGRA)}

\section{UFG BENCHMARKS \& DISALLOWANCE BY OGRA}

OGRA is the regulatory body who monitors the distribution companies by setting of UFG Benchmarks as performance indicators of efficiency. OGRA disallows the losses beyond the Benchmarks by imposing penalty against the inefficiency. But SNGPL and SSGC remains at conflict with gas regulatory body on the Legal Forums in Courts. The controversial issue of Benchmark remains under discussion at significant forums of honourable Supreme Court and the Council of Common Interests Pakistan. However, the year wise tabulated details of UFG Benchmark and Disallowance by OGRA for SNGPL is elaborated in Table I. Moreover the eroding profitability is graphically depicted in Fig.2.

However after much deliberation on the issue of Benchmark, OGRA has agreed to appoint third party commercial Auditor for accurate determination of Benchmark of UFG losses keeping in view the realistic constraints and actual operating conditions of the Company. In order to accomplish the task M/s KPMG Taseer Hadi \& Co Chartered Accountant firm has been appointed by OGRA.

TABLE I. UFG BENCHMARK AND SNGPL'S UFG LOSSES

\begin{tabular}{|c|c|c|c|}
\hline \multirow{2}{*}{ Fiscal Year } & \multicolumn{2}{|c|}{ UFG Benchmarks } & Actual \\
\hline FY & Lower & Upper & SNGPL \\
\hline $2003-04$ & $6.50 \%$ & $6.50 \%$ & $6.65 \%$ \\
\hline $2004-05$ & $6.00 \%$ & $6.00 \%$ & $6.86 \%$ \\
\hline $2005-06$ & $5.70 \%$ & $6.00 \%$ & $6.61 \%$ \\
\hline $2006-07$ & $5.40 \%$ & $6.00 \%$ & $7.77 \%$ \\
\hline $2007-08$ & $5.10 \%$ & $6.00 \%$ & $8.04 \%$ \\
\hline $2008-09$ & $4.80 \%$ & $5.50 \%$ & $8.05 \%$ \\
\hline $2009-10$ & $4.50 \%$ & $5.50 \%$ & $9.63 \%$ \\
\hline $2010-11$ & $4.25 \%$ & $5.00 \%$ & $11.21 \%$ \\
\hline $2011-12$ & $4.00 \%$ & $5.00 \%$ & $10.20 \%$ \\
\hline
\end{tabular}

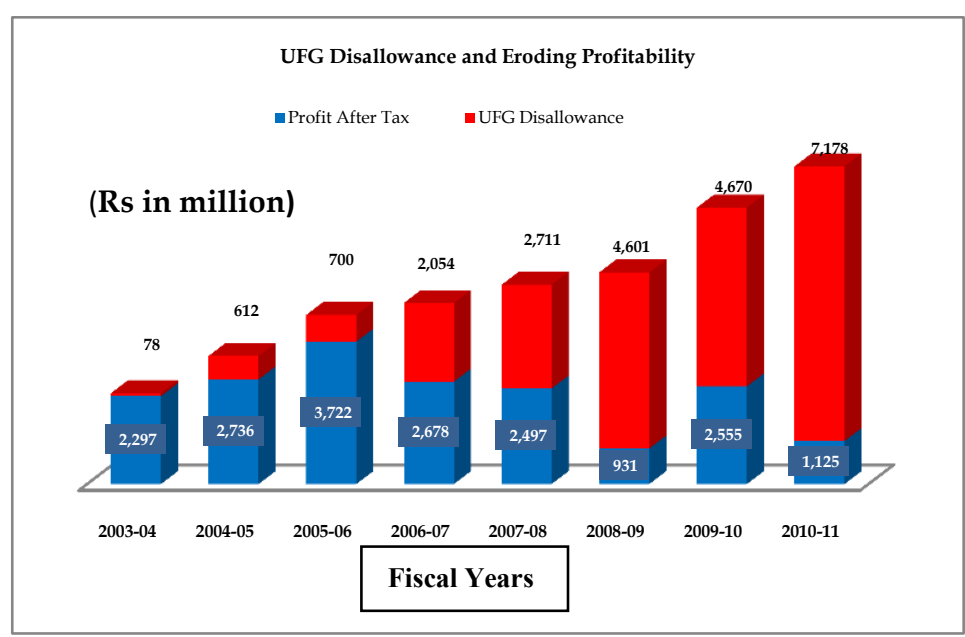

Fig. 2. UFG Disallowance and eroding profitability

\section{MANAGERIAL \& TeChNiCAL Challenges IN LNG DISTRIBUTION}

LNG distribution while using the existing gas pipeline infrastructure of the SNGPL and SSGC is really risky and challenging.

The term SMS refers to Sales Metering Station; (SMS is first point, after transmission network of Gas pipelines from where Gas Sales can be executed to the consumers) where as CMS refers to Consumer metering Station; (CMS is the 
Consumer metering station located on distribution network and gas is measured with gadget at this point for accurate billing to consumer as per actual consumptions in relevance to contractual pressures and Contractual Load Appliances).

SMS cum CMS refers to an assembly when there is no distribution pipeline network between an SMS and CMS meaning that the two stations are constructed having no physical distance between them. This Assembly is helpful in avoiding distribution network losses which is always very problematic due to its leakages, haphazard off-takes for consumers and its overloaded and low pressure conditions. The distribution network's life is low due to its compromised laying and constrained operating conditions.

One condition differentiating transmission and distribution networks is that the transmission network is laid after proper acquisition of right of way (ROW) land which is dedicated with almost no practical interference after its acquisition and it is also maintained by concerned transmission department. However distribution network is laid in the government land and passes along general public areas like along the roads and streets. No Right of Way abbreviated as ROW is dedicated for distribution pipelines and it is hence full of interference arising from surrounding infrastructure developments.

However SMS cum CMS infrastructure can only be used to supply gas to the corporate/large consumers which are located at the end point of transmission pipeline laid on the company's owned right of way (ROW) having negligible losses. But the use of distribution network where there is UFG due to the reasons as discussed earlier, LNG distribution dream can become a nightmare if the associated challenges are not addressed properly.

One of the options is to setup a separate infrastructure which is not financially feasible and a time consuming approach. The CNG Sector has been offered the provision of LNG for running of their businesses but since they are located on the distribution networks and gas passed to distribution network can be consumed by all the retail consumers as well which were actually not the intended clients for LNG. This fact is posing serious technical and managerial threats and challenges to the gas distribution companies and requires business process re-engineering for a feasible business.

These managerial \& Technical challenges are:

1) Pressure Profiling for Leakages \& Measurement Errors of undersized meters

SNGPL is doing the pressure profiling during peak and non-peak hours in preview of reduction of gas leakage losses at reduced pressures. But it is a harsh fact that when the network line pressures are reduced the Corrected flow rate capacity of the meters installed on the network is reduced at the decreased pressures and it introduces gas measurement errors in meters due to under sized capacity in relevance to load.

Therefore if pressures are reduced the leakage losses are reduced but the measurement losses due to undersized meters increases and if pressures are increased it increases the corrected capacity of meters at healthy line pressures but also increases the line losses via leakages.

It is really challenging and tough to manage the optimum balance between the two aspects due to existing network conditions.

\section{2) BULK to RETAIL Volume RATIO in Sales}

The Gas Allocation Policy of Pakistani Government gives top priority to retail sector, to facilitate the general public, where the percentage of gas losses are much higher than the Bulk sector. It is also not the feasible sale for distribution company for the high cost to low benefit ratio.

Moreover, in the past five Years, Gas Distribution Network of SNGPL has been extended by 27,844 KMs which depicts $46.44 \%$ increase in distribution network. Consequently 954,977 Nos. domestic consumers have been added resulting in $30.26 \%$ increase in retail consumers.

The unprecedented growth of new connections during last few years has adversely affected SNGPL bulk to retail ratio. It was 45:55 for Bulk to Retail in fiscal year FY 2003-04 but consequently reduced further to 22:78 in FY 2013-14.

- During 1998-99 to 2005-06 gas input increased by $115 \%$ which was mostly diverted to Bulk sector where UFG loss is minimal, which resulted in reduction of UFG percentage losses from $11.28 \%$ in fiscal year FY $1998-99$ to $6.61 \%$ in FY 2005-06.

- From 2005-06 to 2011-12 the increase in gas input was only $10 \%$ whereas consumption in retail sector increased sharply from $369 \mathrm{BCF}$ in 2005-06 to 517 $\mathrm{BCF}$ in 2011-12 i.e. $40.1 \%$ and Bulk consumption decreased from $244 \mathrm{BCF}$ to $157 \mathrm{BCF}$ i.e. $35.6 \%$ respectively in Bulk sector.

- Gas from bulk sector was diverted to retail sector from $40 \%$ sale in year 2005-06 to $22 \%$ sale in year 2013-14, thereby increasing the percentage UFG loss from $6.61 \%$ to $11.48 \%$.

Therefore choice for adaption of specific Bulk to Retail Ratio in Sales is not available for gas Distribution companies. This is one of the major challenges for these companies.

\section{3) Incorporation of Recovery based Theft Volume detected.}

Company establishes the pilferage/theft volumes against the gas pilferers strictly in line with OGRA's Procedure of Dealing with Theft of Gas Cases. As per the prevailing practice, the volume allowed in gas sales is linked with recovery. Whenever theft volumes are charged to gas pilferers they manage to get relief from the courts in form of stay orders and thus the established theft volumes remain unrecovered till the decision of the case, which takes several years. The above criterion followed by OGRA is causing unbearable loss. The real Efforts of the company in identifying the theft cases and establishing the pilferage volumes do not yield the fruitful results for being recovery based volumes. The gas pilferers use the procedural hitches for their advantage. 
It is a matter of fact that only approximately $60 \%$ of the theft amount booked is recovered whereas rest remains pending at litigation forums. Moreover, in large number of cases, consumers default to pay the booked charges thus resulting in non recovery of theft charges as well as accumulation of bad debts. The non-consumer theft recovery cases are even less than $1 \%$ of total.

Therefore a lot of energy of company is invested on an aspect where there is hundred percentage risk of effort materialization. It is fruitful in case of some recovery to consider the theft volume incorporation while calculating UFG loss Percentage.

\section{4) Human Resource}

- (Unionized and politicized Subordinate Staff)

The Human Resource of these companies is categorized as

$\checkmark$ Management/Executives (Top, Middle and Lower Management)

$\checkmark$ Permanent Subordinate Staff

$\checkmark$ Daily Wages / Casual Employees

The Permanent subordinate staff is having a political representative body known as labor union. The subordinate staff of the distribution companies is unionized and politicized human resource. Such a structure is always offering great resistance towards any change in policy for improvement of efficiency or work norms. The staff member which are hired on Blood Quota basis are often just a useless addition to the number count while maintaining the absenteeism or even worse by involvement in notorious activities for ulterior motives. These unionized and politicized human resources are headache for the management. Effective implementation of plans and policies is not possible with such staff members. The CBA (Collective Bargaining Agreement) representative body, also known as labor union, which is principally supposed to safeguard Staff's rights, have become contaminated bodies with political influence of sponsor employees. The funding for election campaign of these unions often comes from the subordinate employee corners which invest black money to yield a larger personal interest at later stages. Such type of staff is a permanent liability for the company and managing them is a major challenge.

The casual staff is also hired and is largest in number more than permanent staff employees and executives. Although there are many associated issues arising from their presence but most prominent effect is a large and rapid turnover in company. Therefore no consistent quality of work can be maintained for long.

The lower level executives are the immediate line managers who are supposed to first interact with these staff for work execution. The lower executives/first line managers often feel tensed as there is pressure from management to yield results and achieve targets but on the other hand the CBA and labor union are creating problems for them. This all staff alignment is a major challenge to achieve the desired level of work quality in order to avoid UFG losses.
Therefore challenge remains there to optimize the human resource efficiency while managing all these odds.

\section{5) Over Riding Effects}

Apart from the efforts being made by the Company, there are some overriding effects which are badly hampering SNGPL efforts. Some of such factors are as follows:

\section{a) Electricity crisis}

The prevailing electricity crisis in the country is also affecting the efficiency of Gas Company. It has not only affected the measurement accuracy in domestic sector but due to long lasting power shut downs network protection is not possible. This has rendered underground gas pipeline network unprotected, which has resultantly aggravated the underground leaks due to poor cathodic protection against corrosion.

A large number of domestic and commercial consumers are using gas fired electric generators to overcome the electricity crisis. This has undersized the low capacity domestic meters. Moreover fiddling with gas regulators and tampering with meters has become a common phenomenon. This is an overriding effect for Distribution losses.

\section{b) Shortage of Gas}

Due to shortage of gas and restrictions on new gas connections, the trend of unauthorized/illegal connections has increased manifold. Although Company is making a continuous effort in identifying and disconnecting illegal connections/networks, making the lives of field staff at risk but still some of the individuals backed by influential people succeeded in reconnecting the illegal networks time and again. The fast growing development network is yet another challenge that the Company is facing i.e. hampering SNGPL efforts against the gas losses.

a) Measurement inaccuracies due to low pressures in the System

The existing continuous low pressures in system has increased the tendency of meter defects due to wear and tear of internal parts because of increased velocity and travel of dust and gas condensate in meter body.

\section{6) Capacity Constraints and over flexible HR Structure}

The capacity building of the distribution company has not been on concrete grounds in the past. The HR structure is very flexible as per doctrine of necessity. The Job Descriptions and KPIs (Key Performance Indicators) are very flexible and there is no hard and fast rule for the transfers or job assignments.

Sometimes officer of a higher cadre from senior management is performing a job which later on, is assigned to another person from middle management. At times even officer from junior management is assigned with the same job descriptions and assignments. Although it is already under consideration by management but there is a lot of room for improvement.

Even the role of same department is not uniform and vary from Region to Region based on the personal preferences of the Managers. This has completely spoiled the capacity building of the company. Moreover it is a source of capacity 
constraint. There is no concrete professional level achievement by a specific department.

The executives and staff keep on switching within departments. Due to random shifts and transfers the work is seen to start from ab-initio in a Section by the advent of irrelevant new comers from other departments and the fresh inductions working without any supervision. This is a serious capacity gap and need assessment for betterment of the company affairs.

\section{CONCLUSIONS}

The LNG Import Contract is a good idea but the distribution of LNG using the same existing gas pipeline infrastructure of gas distribution companies (SNGPL \& SSGC) in full length without any change in existing infrastructure or policies is definitely not feasible.

The existing structures of the gas distribution companies are having complicated problems ranging from poor operating Network conditions to Human Resource management Problems.

There are capacity constraints in gas Distribution companies for long term control on the gas network losses. Most of the times fire fighting is carried out to yield short span results.

Initially LNG distribution should be confined to Corporate Sectors only where the giant consumers are located at the end of transmission mains without involvement of distribution network. However a concrete re-structuring of infrastructure should be carried out by network segmentations before expansion of R-LNG distribution.

However the other consumers located on the distribution network of SNGPL or SSGC must be filtered properly and supplied with the LNG having dedicated pipelines.

If LNG is intended to benefit the other bulk and retail consumers located on distribution lines then another proposal is to dedicate an SMS on the transmission network of each Region and at that SMS R-LNG can be provisioned with the facility for filling it in cylinders after compression. This can eliminate the risk of UFG losses related to the distribution of costlier LNG fuel.

The policies for developmental activities must be made realistic in the light of Principles of Quality Management System Standards which requires "Factual Approach to Decision making".

The companies should be encouraged to allow provision of new connections on fast track basis.

The activities which are provoking unnecessary litigation must be avoided. The cost benefit Analysis of the policies must be carried out by OGRA and shared with the decision makers in Ministry of Petroleum \& Natural Resources Pakistan. This would ease out many operational constraints and help in capacity building of the energy distribution companies.

The realistic approach must be adapted for every project which is under consideration at any forum for solution of energy crisis in Pakistan along with infrastructure analysis of the existing distribution pipeline network. The realignment of infrastructure and policy modification is must for making an effective and successful plan for sustainable solution of Energy crises in Pakistan

\section{RECOMMENDATIONS}

Recommendations for Combating these challenges are:

$\checkmark \quad$ The interconnected network should be isolated into proper segments/small pockets which are totally independent and reconciled by installation of check meters in the Central Database at the end of every monthly billing cycle.

$\checkmark$ The company should be empowered to decide the choice of consumer for its R-LNG Sale.

$\checkmark \quad$ Network Rehabilitation should be a separate project and should be carried out independent of operational departments.

$\checkmark \quad$ The Decision making powers should be transferred to middle and lower level management for effective control and monitoring.

$\checkmark$ The Standard operating procedures should be uniformly implemented across the different distribution Regions.

$\checkmark \quad$ The hierarchy and allocation of resources should be based on realistic workloads.

$\checkmark$ The absenteeism among employees should be eliminated and those which are overburdened should be given realistic work.

$\checkmark$ The de-centralization of Decision making and empowerment of Gas Distribution Regions should be carried out.

$\checkmark$ All departments should be mobilized following the theme of Total Quality Management (TQM) Principles to streamline the company operations and processes.

$\checkmark$ The interloping of gas network to address the winter low pressure complaints must be stopped and fluid dynamics study should be carried out. Then based on this study gas network modification and rectification should be carried out.

$\checkmark \quad$ Team building approach for productive working units of human resource should be promoted to harness the better results.

The company's departmental managers and line managers should be taught the philosophy of TQM to control the business and operational processes in proficient manner. The approach for leaving the responsibility of controlling the UFG losses for a specific department must be discarded and every department and every person must control his share of poor workmanship to stop contributing to UFG losses. Before such measures company should confine to only pilot project distribution of R-LNG as it would bring bad debts to the business if done in the traditional way. 
Only after adapting new sustainable approach the company should move to massive scale handling of LNG import Project.

\section{FUTURE WORK}

This project can be extended to explore a feasible infrastructure for Energy Sector in the light of TQM (Total Quality Management) principles of ISO-9001. The TQM approach can be applied for quality energy infrastructure to avoid the associated challenges and avoid perspectives of failure while implementing new solutions for Energy Requirements. The Process Re-Engineering approach should be adapted in business traits to achieve sustainable results.

\section{REFERENCES}

[1] Arshad H. Abbasi, Maha Kamal. , "Importing Liquefied Natural Gas (LNG): A Policy Analysis"Sustainable Development Policy Institute.
[2] Muhammad Munir, Muhammad Ahsan, Saman Zulfqar, "Iran-Pakistan Gas Pipeline:Cost-Benefit Analysis", Journal of Political Studies, Vol. 20, Issue-2,2013,161:178.

[3] "LNG: The Whole Truth", The News Saturday May 02, 2015 Print Edition.

[4] Draft of Gas Sales Agreement (GSA)

[5] Draft of Joint Venture Agreement for the development of a liquefied Natural Gas Project.

[6] Draft of Petroleum Law

[7] Draft of Master Sales Agreement for the sale and purchase of liquefied natural gas spot cargos delivered on an ex-ship basis.

[8] Draft of LNG Terminal Use Agreement (Version 2)

[9] OGRA notification, Islamabad the 1st January, 2013, S.R.O. (I)/2012.Insupersession of its notification No.S.R.O.1497(I)/2012, dated 31st December, 2012.

[10] Mike Haydell, "Unaccounted-For Gas", Reliant Energy-Entex P.O Box 550, New Iberia , LA 70562-0550

[11] UFG, Accounts and Annual Reports. 